\title{
The ACRL awards program, 1992
}

\author{
By Carolyn De Bonnett
}

ACRL Program Assistant for Membership and Chapters

\section{Check out these award-winning opportunities and honors.}

$\mathbf{T}$ he Association of College and Research Libraries (ACRL) sponsors a number of award programs on behalf of academic or research librarianship to recognize special achievements and outstanding publications and to foster professional growth. Someone you know is deserving of special recognition for their contributions to academic and research librarianship. Take a moment to nominate these outstanding individuals so that they can get the recognition they deserve. Award-winning opportunities for you and your colleagues are described below. Please review the requirements for each award program and note the programs for which you or a colleague are eligible.

General submission procedure: Unless otherwise indicated, send nominations and applications to: (Name of Award), Association of College and Research Libraries (ACRL), American Library Association, 50 East Huron Street, Chicago IL 60611.

Staff contact: If you have questions or need help in compiling a nomination contact: Carolyn R. De Bonnett, (800) 545-2433 ext. 2510 or (312) 2802510 .

\section{ACHIEVEMENT/DISTINGUISHED SERVICE}

\section{Academic or Research Librarian of the Year Award}

Purpose: To recognize an individual member of the library profession who is making an outstanding national or international contribution to academic or research librarianship and library development.

Donor: Baker \& Taylor Books donates the $\$ 3,000$ cash prize.
Criteria: Nominees should have demonstrated achievements in such areas as:

1. Service to the organized profession through ACRL and related organizations.

2. Significant and influential research on academic or research library service.

3. Publication of a body of scholarly and/or theoretical writing contributing to academic or research library development.

4. Planning and implementing a library program of such exemplary quality that it has served as a model for others.

Over $\$ 13,000$ in cash prizes, an all-expenses paid trip to Europe, and special recognition from your peers are available to you, courtesy of ACRL.

Submission procedures: Provide supporting reasons for this nomination on each of the four criteria. Please attach a current vita - not a biographical sketch - and send in eight (8) copies of the nomination materials to ACRL. Note: Please do not solicit supporting letters seconding your nomination. Such letters will not be considered in the Award Committee's decision.

Deadline: December 1, 1991.

Previous recipients: Keyes D. Metcalf and Robert D. Downs (1978); Henriette D. Avram and 
Frederick G. Kilgour (1979); Evan Ira Farber(1980); Beverly P. Lynch (1981); William Budington (1982); Richard M Dougherty (1983); Richard D. Johnson (1984); Jessie Carney Smith (1985); Margaret Beckman (1986); Duane Webster (1987); Edward G. Holley (1988); John P. McGowan (1989); Patricia Battin (1990); Richard De Gennaro (1991).

\section{Miriam Dudley Bibliographic Librarian Award}

Purpose: To recognize an individual librarian who has made an especially significant contribution to the advancement of bibliographic instruction in a college or research institution. The award honors Miriam Dudley, whose pioneering efforts in the field of bibliographic instruction led to the formation of the ACRL Bibliographic Instruction Section.

Donor: Mountainside Publishing Company donates the $\$ 1,000$ cash award on behalf of its publication, Research Strategies: A Journal of Library Concepts and Instruction. The award is administered by the Bibliographic Instruction Section of ACRL.

Criteria: Nominees should have achieved distinction in one or more of the following areas:

1. Planning and implementation of an academic bibliographic instruction program that has been a model for other programs nationally or regionally.

2. Production of a body of research and publication that has a demonstrable impact on the concepts and methods of teaching and information-seeking strategies in a college or research institution.

3. Sustained participation in organizations, at the national or regional level, devoted to the promotion and enhancement of academic bibliographic instruction.

4. Promotion, development, and integration of education for bibliographic instruction in ALAaccredited library schools or professional continuing education programs that have served as models for other courses and programs.

Submission procedure: Write a letter outlining how the candidate meets the above criteria. Nominees need not necessarily meet all the criteria. Please attach a current vita-not a biographical sketch. Send nominations to: Betsy Wilson, Chair, Miriam Dudley Award Committee, Undergraduate Library, University of Illinois, $1408 \mathrm{~W}$. Gregory Drive, Urbana, IL 61801. Call Betsy Wilson if you have questions or need assistance in compiling nomination forms. Phone: (217) 333-3489. Note: Nominees will be judged on an individual basis; this award cannot be given to a pair or group of persons.

Deadline: December 1, 1991.

Previous recipients: Thomas Kirk (1984); Carolyn Kirkendall (1985); Virginia Tiefel (1986); Evan Ira Farber (1987); Sharon Hogan (1988); Maureen
Pastine (1989); Joan Ormondroyd (1990); Carla Stoffle (1991).

\section{Hugh Atkinson Memorial Award}

Purpose: The award honors the life and accomplishments of Hugh C. Atkinson, one of the major innovators in modern librarianship, and recognizes outstanding achievement (including risk-taking) by academic librarians that has contributed significantly to improvements in the area of library automation, library management, and/or library development or research.

Donor: The award is jointly sponsored by ACRL, the Association for Library Collections and Technical Services (ALCTS), the Library Administration and Management Association (LAMA), and the Library and Information Technology Association (LITA), four divisions of ALA, and is funded by an endowment created by divisional, individual, and vendor contributions given in memory of Hugh $\mathrm{C}$. Atkinson. Additional funds are sought to bring the endowment to at least $\$ 100,000$. Send your taxdeductible contributions to Hugh Atkinson Memorial Award, ACRL/ALA, 50 East Huron Street, Chicago, IL 60611. The award consists of an unrestricted $\$ 2,000$ cash prize and a plaque.

Eligibility: The nominee must be a librarian employed in a university, college, or community college library in the year prior to application for the award and must have a minimum of five years of professional experience in an academic library. Individuals may nominate themselves or be nominated by others.

Criteria: The nominee must have demonstrated achievement (including risk-taking) that has contributed significantly to improvements in the area of library automation, library management, and/or library development or research.

Submission procedure: Those wishing to nominate someone (including themselves) for the award should write a letter to ACRL outlining how the candidate meets the above criteria. Letters should be accompanied by a current copy of the candidate's vita.

Deadline: December 1, 1991.

Previous recipients: Richard M. Dougherty (1988); Thomas Michalak (1989); Russell Shank (1990); Donald E. Riggs (1991).

\section{EBSCO Community College Learning Resources Achievement Awards}

Two annual awards to recognize significant achievement in the areas of: 1) program development and 2) leadership or community service.

Donor: EBSCO Subscription Services will provide $\$ 500$ for each of the awards along with a plaque for each award winner. 
Eligibility: Individuals or groups from two-year institutions, as well as the two-year institutions themselves, are eligible to receive awards. Nominations will be kept on file for three consecutive years.

Criteria: Nominees for the Program Development awards should have demonstrated significant achievement in one of the following areas: development of a unique and innovative learning resources/ library program that enhances use by faculty and students; integration and exploration of media and technology to enhance services; exemplary collection development policy model. Nominees for the Leadership of Community Service award must have made significant achievement in one or more of the following areas: advocacy of learning resources/libraries by individuals, groups, or programs not directly affiliated with the program; community services (including businesses, public libraries, special services for the disadvantaged); cooperative programs with schools, libraries, and other organizations; legislative advocacy; special assignments associated with the mission of the community colleges such as literacy across the curriculum programs.

Submission procedure: Nominations should consist of the application form, a narrative letter describing the achievements, and any supporting attachments. Send four (4) copies of the nominations to: Award Jury Chair, Marilyn MacDonald, Dean of Instructional Services and Libraries, Foothill College, $12345 \mathrm{El}$ Monte Road, Los Altos Hills, CA 94022-4599; (415) 949-7721.

Deadline: December 1, 1991.

Previous recipients: Charles R. Peguese (Leadership or Community Service) and Cooperative Collection Development Committee of the Chemeketa Cooperative Regional Library Services (Program Development $\rangle(1990)$; James O. Wallace (Leadership or Community Service) and Jimmie Anne Nourse and Rudy Widman (Program Development) (1991).

\section{PROFESSIONAL DEVELOPMENT AND RESEARCH}

\section{Doctoral Dissertation Fellowship}

Purpose: To foster research in academic librarianship by encouraging and assisting doctoral students in the field with their dissertation research.

Donor: The Institute for Scientific Information donates the $\$ 1,000$ cash award and citation.

Eligibility: The recipient of the fellowship must meet the following qualifications:

1. Be an active doctoral student in the academic librarianship area in a degree-granting institution.

2. Have completed all coursework.

3. Have had a dissertation proposal accepted by the institution.
4. A recipient of the fellowship may not receive it a second time.

5. The applicant need not be an ACRL member.

Criteria: The proposal will be judged primarily on merit with emphasis on the following:

1. Potential significance of the research to the field of academic librarianship. (No attempt will be made to define academic librarianship but the subject should be consistent with topics usually published in College \& Research Libraries or presented at ACRL meetings.)

2. Validity of the methodology and proposed methods of analysis.

3 . Originality and creativity.

4. Clarity and completeness of the proposal.

5. Presentation of a convincing plan for completion in a reasonable amount of time.

6. Evidence of a continuing interest in scholarship such as a previous publication record.

Submission Procedure: Qualified students who wish to be considered for the fellowship may apply by submitting a brief (ten pages or less doublespaced) proposal that includes the following:

1. Description of the research, including significance and methodology.

2. Schedule for completion.

3. Budget and budget justification for items for which support is sought. (Must be items for which no other support is available.)

Examples of acceptable budget items are printing, computer time, fees to subjects, keypunching, statistical consulting, photography, art work, typing, and professional travel.

4. Name of dissertation advisor and committee members.

5. Cover letter from dissertation advisor endorsing the proposal.

An up-to-date curriculum vitae should accompany the proposal. Because of limits imposed by timing considerations, applications may be made for research under way; e.g., a student who begins research in the fall may apply for support for expenses incurred from the fall until the time the award is made.

Deadline: December 1, 1991.

\section{Martinus Nijhoff International West European Specialist Study Grant}

Purpose: The annual grant supports a wide variety of research topics pertaining to Western European studies, librarianship, or the book trade. Proposals may focus on the acquisition, organization, or use of library materials from or relating to Western Europe. Current or historical subjects may be treated in the research. The objectives of the study may be of either practical use or scholarly value to the community of librarians, scholars, and publishers. 


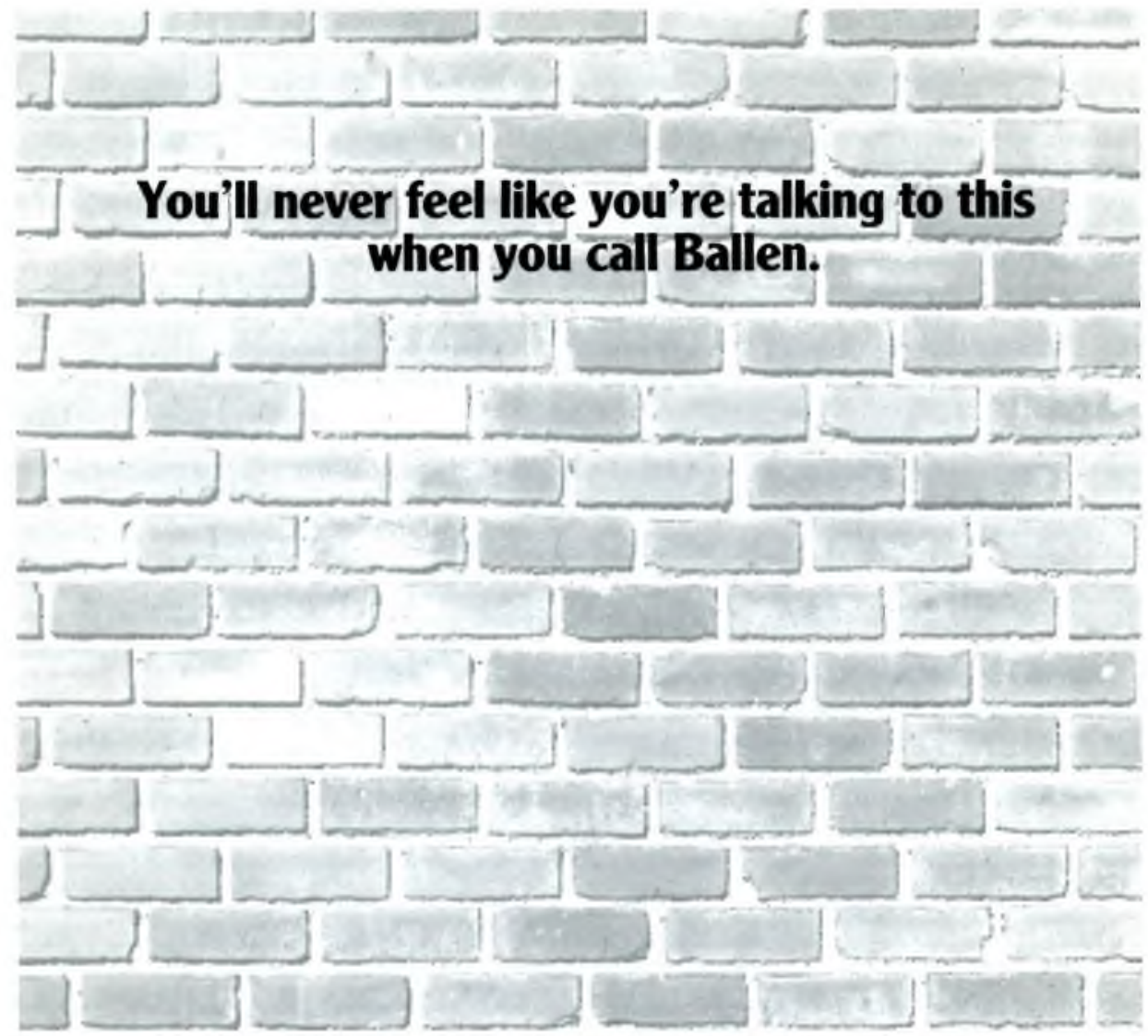

When speaking with some booksellers, you might as well be talking to the wall. But at Ballen, all our employees have dedicated themselves to customer service. And regardless of the size of your library, you'll always receive the utmost in personal attention.

All of our customers receive their very own customer service representative. We also offer many value-added services, like BallenNet, our exclusive online system. And our "electronic mailbox" will enable you to send claims and obtain important information instantly. Plus, if you need to reach a Ballen officer, you can do so by picking up the phone.

For more information, call Ballen at (800) 645-5237. Because when you talk, Ballen listens.

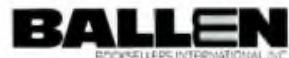

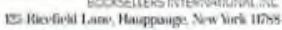

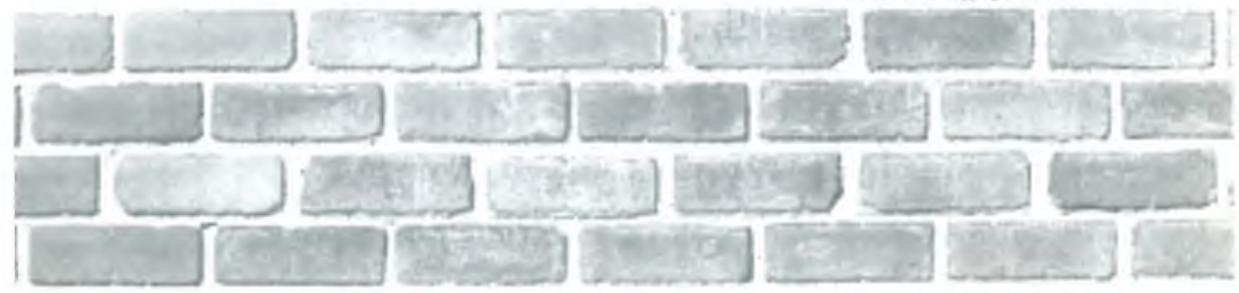


Donor: Martinus Nijhoff International, subscription agent and book dealer with headquarters in the Netherlands, funds this study grant which covers air travel to and from Europe, transportation in Europe, and lodging and board for no more than fourteen (14) consecutive days. A maximum amount of 10,000 Dutch guilders - or U.S. dollar equivalent - is awarded each year. Funds may not be used for salaries, research-related supplies, publication costs, conference fees, or equipment purchases.

Criteria: The primary criterion for awarding the grant is the significance and utility of the proposed project as a contribution to the study of the acquisition, organization, or use of library materials from or relating to Western Europe. The award jury will review proposals with the following in mind:

1. What is the work to be accomplished? The proposal should be as explicit as possible about the current state of knowledge in the area and what the successful completion of the study will achieve.

2. What is the need for and value of the proposed research? The proposal should provide persuasive evidence that the study is of practical use or scholarly value to the wider community served by the grant.

3. What is the methodology for carrying out the proposed work? The research design should be as specific as possible and demonstrate why the European component is essential.

4. Is the work accomplishable within the time frame proposed? If the study extends beyond the 14-day limit of the grant, the proposal should specify how the additional work will be completed and funded.

5. Are the applicant's qualifications sufficient to carry out the study?

Submission procedures: $\operatorname{Six}(6)$ copies of the application should be submitted and must include:

1. A proposal, five (5) pages or less, typed doublespaced.

2. A tentative travel itinerary not to exceed 14 days, including the proposed countries and institutions to be visited and the preferred period of study/ travel.

3. A travel budget, including estimated roundtrip coach airfare, transportation in Europe, lodging expenses, and meal costs.

4. A current curriculum vitae.

Obligations of the grantee: The recipient's detailed expense statement, with original receipts, is due to ACRL within two months of the trip's termination. The grantee is required to submit a report to ACRL within six months of no less than 4,000 words on the research resulting from the study trip. It is assumed that in most cases this report will be suitable for publication; if so, ACRL is given the first right of refusal. The grantee should submit an abstract of the report for publication in the WESS Newsletter. In addition, the grantee may be asked to participate in a WESS general discussion group, advise the award jury, or counsel new grantees. Recipients are encouraged, but not required, to join WESS and hecome involved in its activities.

Deadline: December 1, 1991

\section{Samuel Lazerow Fellowship for Research in Acquisitions or Technical Services in an Academic or Research Library}

Purpose: To foster advances in acquisitions or technical services by providing librarians a fellowship for travel, or writing in those fields. Research projects in collection development or the compilation of bibliographies will not be supported by this fellowship.

Donor: The Institute for Scientific Information funds the fellowship which consists of a $\$ 1,000$ cash award and a citation.

Criteria: The proposals will be judged with an emphasis on the following:

1. Potential significance of the project to acquisitions or technical services work.

2. Originality and creativity.

3. Clarity and completeness of the proposal.

4. Evidence of an interest in scholarship, such as a previous publication record.

Submission procedure: Brief proposals (five pages or less, double-spaced) should include the following:

1. Description of research, travel, or writing project.

2. Schedule for project.

3. Estimate of expenses. (Examples: professional travel, computer time, photocopying, typing.)

4. Recipients of the fellowship will be asked to submit a brief report of the results of their research.

5. An up-to-date curriculum vitae should accompany proposal.

Deadline: December 1, 1991.

\section{Professional Liaison Awards}

Purpose: To support membership liaison activities in other (non-library) professional associations.

Donor: ACRL provides the funding which is distributed through the Professional Liaison Committee. Ten (10) awards of up to $\$ 400$ each are available.

Eligibility: Applicants must be a member of ALA. Preference is given to ACRL members.

Criteria: Preference will be given to efforts which contribute to the understanding or use of academic library resources or services. Also eligible for funding are efforts which enhance the perception of academic librarians as part of the "education team." Support for participation in organizations could include activities such as major presentations, panel 
discussions, poster sessions, publications of articles, and more. In awarding the funding request, the committee will give weight to the significance of the contribution.

Funding will be up to $\$ 400$ of costs not covered by others for travel, accommodations, and registration (not membership). Funding will be awarded after the event, but a request may be submitted for approval prior to the event. Awards are dependent on the committee receiving report of activity.

Submission procedure: The following format should be followed:

1. Name, title, address, and telephone number of requester.

2. Name of organization sponsoring the program.

3. Requester's relationship to organization.

4. Summary of participation (e.g., abstract of paper).

5. Statement of potential impact for promoting academic or research librarianship.

6. Budget and amount being requested.

7. Supporting documentation as relevant (e.g., receipts, program, etc.).

Applications should be sent to the chair of the Professional Liaison Committee, Melvin R. George, 2979 NW 13th Street, Corvallis, OR 97338; (503) 754-3412.

The committee may request information suitable for publication within six months after the event.

Deadline: The committee meets twice a year to review applications at ALA Midwinter Meetings and Annual Conference.

\section{PUBLICATIONS OR ARTICLES}

\section{Katharine Kyes Leab and Daniel J. Leab American Book Prices Current Exhibition Catalogue Awards}

Purpose: To recognize outstanding catalogs published by American or Canadian institutions in conjunction with exhibitions of books and/or manuscripts.

Donor: Katherine Kyes Leab and Daniel J. Leab, American Book Prices Current, established an endowment to fund the awards which consist of printed citations to the winning institutions organizing the exhibitions.

Eligibility: Catalogs published by American or Canadian institutions in conjunction with an exhibition of books and/or manuscripts which has taken place or which is in progress before August 31, 1991, are eligible. Catalogs must be published between September 1, 1990, and August 31, 1991. The entries will be divided into three budget categories - expensive, moderately expensive, and inexpensive-based upon the production costs as outlined in the entry form. Catalogs may be of varying formats, styles, and scope, but each must represent an exhibition which has taken place. Catalogs may be intended for various types of audiences: e.g., scholars; students; general public. Catalogs may have various purposes: e.g., publicity, dissemination of information about a collection, attraction of donations, commemoration of a special occasion, etc.

Criteria: Catalogs will be judged on the level of accuracy and consistency of presentation, their clarity, quality of design, and usefulness to the intended audience.

Submission procedure: Four (4) copies of the catalog must be submitted with an entry form (available from the committee chair) to the chair: Marvin J. Taylor, Special Collections, Columbia University, Health Sciences Library, 701 W. 168th Street, New York, NY 10032. All catalogs submitted will become the property of RBMS. If you have any questions, call Marvin Taylor at (212) 305-7931.

Deadline: September 30, 1991.

\section{K.G. Saur Award for Best Article in College \& Research Libraries}

Purpose: To recognize the most outstanding article published in College \& Research Libraries during the preceding volume year.

Donor: K.G. Saur donates a $\$ 500$ cash award to each author and an appropriate citation.

Eligibility: Articles published in College \& Research Libraries during the preceding volume year.

Criteria: The winning article will be selected on the basis of originality, timeliness, relevance to ACRL areas of interest, and quality of writing

Submission procedure: Articles for College d Research Libraries may be submitted to the editor: Gloriana St. Clair, Assistant Dean for Access Services, E506 Pattee Library, Pennsylvania State University, University Park, PA 16802.

\section{Call for popular papers}

The Popular Culture Association will be meeting in Louisville, Kentucky, from March 18-21, 1992. Scholars who work in all aspects of popular culture will meet and share common interests. Anyone who is interested in presenting a paper on a topic related to popular culture and libraries should write or call: Allen Ellis, Associate Professor of Library Services, W. Frank Steely Library, Northern Kentucky University, Highland Heights, KY 41099-6101; (606) 5725527, Fax (606) 572-5390, by September 30, 1991. 